\title{
Correspondence
}

\section{Generalized eruptive keratoacanthoma of the Grzybowski type: some considerations on treatment and pathogenesis}

Dear Editor,

A 64-year-old male patient presented with a 2-month history of a generalized mucocutaneous eruption characterized by suspected keratoacanthomas (KAs), umbilicated papules, and small follicular papules, which mainly involved the face, upper limbs, and trunk; the oral mucosa was affected as well (Fig. 1a-c).

Histopathologic analysis of several lesions revealed the typical features of KA (Fig. 2a and b). Both the absence of similar cases in the patient's family and the late onset of these skin tumors made a familial form of KA unlikely. A diagnosis of generalized eruptive keratoacanthoma (GEKA) was made. No concomitant head and neck/oropharyngeal carcinoma was present.

Due to the intense itching, the progressive onset of new lesions involving more and more extensive mucocutaneous areas, and the negative impact on his quality of life, we decided to treat the patient with acitretin $20 \mathrm{mg} /$ day and topical tretinoin $0.05 \%$ cream once a day. Marked improvement was observed at the end of the second month of combined treatment (Fig. $1 a^{\prime}-c^{\prime}$ ).

GEKA, first described by Grzybowski, is a very uncommon variant of KA with unknown etiology ${ }^{1,2}$ that involves widespread areas of the skin. The course of the disease is chronic, and its response to therapy is usually poor or partial. There are several studies focused on the relationship between human papillomaviruses (HPVs) and KA, especially in the solitary form. ${ }^{3,4}$ On the other hand, only a few studies have addressed the prevalence of viral sequences in multiple KAs. ${ }^{5,6}$ In particular, Forslund et al. $^{3}$ and Stockfleth ${ }^{4}$ detected the presence of cutaneous HPV DNA by the use of PCR in $20-50 \%$ of specimens obtained from keratoacanthomas patients. Strumia et al. ${ }^{5}$ found HPV-16 with a high prevalence in KAs and normal skin from immunocompetent individuals. On the contrary, Haas et al. $^{6}$ failed to detect HPV-positive biopsy specimens in a patient with a 9-year history of generalized eruptive KA of the Grzybowski type.

In order to assess possible involvement of viral infections in the pathogenesis of this GEKA, we analyzed a skin biopsy of a retroauricular lesion by nested PCR for the presence of HPV together with specific human herpesviruses (HHVs) that have a possible association with skin lesions: the $\alpha$-herpesviruses (herpes simplex virus types 1 and 2 [HSV-1, HSV-2] and varicella- zoster virus $[\mathrm{VZV}])$, the human $\beta$-herpesvirus type 6 (HHV-6), and the Kaposi's sarcoma-associated $\gamma$-herpesvirus (HHV-8).

Isolation of DNA was performed as previously described. ${ }^{7}$ We avoided specimen contamination by keeping the DNA extraction area strictly separated from the PCR mixture preparation and sample handling. PCR analysis was performed in triplicate for each set of primers. We used positive (viral genomic DNA) and negative (PCR mixture without DNA template) controls. The sensitivity of the PCR reactions was determined by amplification of known amounts of target sequences (data not shown). To test the absence of major PCR inhibitors, the same amount of DNA used for virus-specific PCR analysis was amplified for human beta actin gene ${ }^{8}$. Nested PCRs for VZV, HHV-6, HHV-8, HSV-1, and HSV-2 were performed as previously described. ${ }^{7}$ Because of the low amount of DNA that was available from the skin biopsy, it was necessary to select the HPV genus to be analyzed. HPV genera beta, gamma, mu, and nu are considered to be correlated with benign cutaneous lesions, and only occasionally have they been found in skin cancers, ${ }^{9}$ with cutaneous $\beta$-HPVs that are ubiquitous in the general population. ${ }^{10}$ On the contrary, HPV-6/11, usually associated with mucosa, were frequently found in benign, premalignant, and malignant cutaneous lesions. ${ }^{11}$ Since the significance of the presence of HPV 6/11/16 in skin lesions remains unknown, we selected to evaluate these specific HPV types. HPV DNA presence was determined using a nested PCR as previously described. ${ }^{8}$ HPV-16 DNA presence was determined using a nested PCR specific for HPV-16-E6 region that we set up within the original amplicon published by Ferre and Garduno ${ }^{12}$ and a nested PCR with degenerate primers already described by de Roda Husman et al. ${ }^{13}$

Our data revealed only the presence of HPV-16 DNA among the viruses analyzed (Fig. 2), while HHVs were not present in the biopsy, even using high sensitive nested PCRs.

The presence of HPV-16 DNA harbored in GEKA lesions does not allow any conclusive consideration on the etiological role of HPV infection and the role of HPV in keratoacanthomas remains thus elusive. However, its potential involvement in the pathogenesis of this disorder supports the retinoids as the first therapeutic option. Retinoids could be effective in GEKA treatment not only because of their antitumor properties but also by altering keratinization and inhibiting HPV replication and assembly. ${ }^{14}$ In keeping with this, an inverse relation has been observed between concentration of retinoids and HPV DNA within infected epithelial cells. ${ }^{15}$ We recommend the evaluation of the role of HPV infection in GEKA as meritorious of further investigation. 

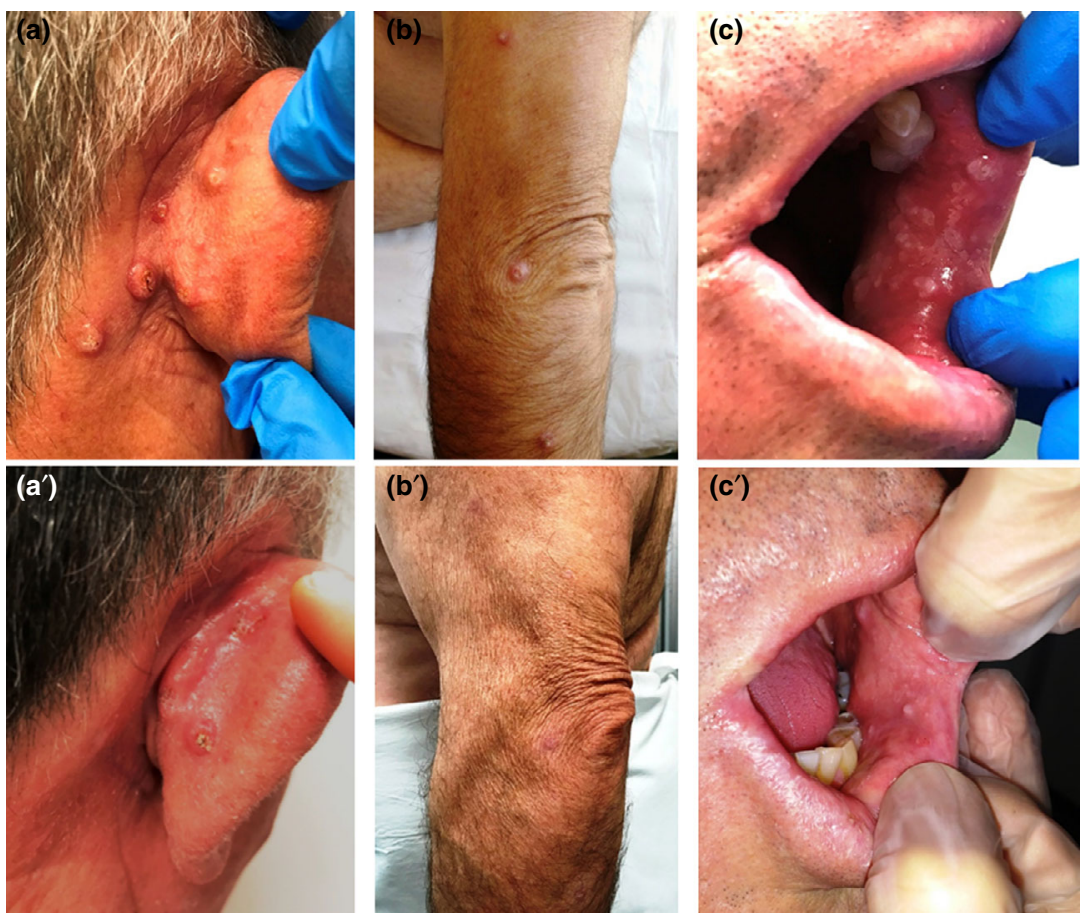

(c)
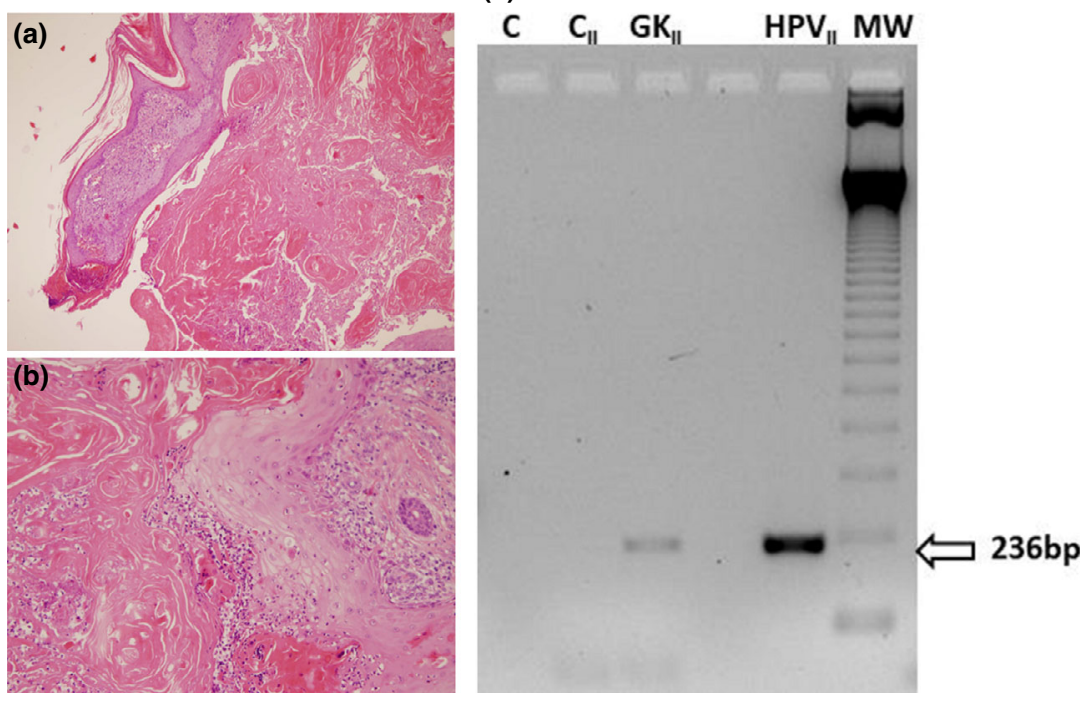

Figure 1 Generalized eruptive keratoacanthomas of the Grzybowski type at patient presentation (a-c); (a) large umbilicated and smaller papules located on the patient's retro-auricular region; (b) typical keratoacanthomas located on his left arm; (c) small papules in the oral mucosa. The same mucocutaneous regions after a 2month treatment with acitretin and topical tretinoin $\left(a^{\prime}-c^{\prime}\right)$

Figure 2 ( $a$ and $b$ ) Histopathology of a retroauricular skin lesion showing features of keratoacanthoma (hematoxylin and eosin, original magnification (a) $\times 20$, (b) $\times 100)$. (c) Presence of HPV-16 DNA by nested PCR in the same skin biopsy reported in this Figure ( $a$ and $b)$. Gel electrophoresis of the nested PCR. $\mathrm{MW}=123 \mathrm{bp}$ (base pair) DNA ladder; $\mathrm{C}$ and $\mathrm{C}_{\|}=$no template DNA (PCR negative control); GK = DNA sample from a skin biopsy of a retroauricular region affected by GEKA of Grzybowski; HPV and $\mathrm{HPV}_{\text {II }}=$ amplicon of $1 \mathrm{ng} \mathrm{HPV-16} \mathrm{DNA}$ as positive control

$$
\begin{array}{r}
\text { Antonella Rotola }{ }^{1}, \mathrm{PhD} \\
\text { Dario Musmeci }{ }^{2}, \mathrm{MD} \\
\text { Valentina Gentili }^{1}, \mathrm{PhD} \\
\text { Domenico Reale }^{3}, \mathrm{MD} \\
\text { Alessandro Borghi }{ }^{2 *}, \mathrm{MD} \\
\text { Roberta Rizzo }{ }^{1}, \mathrm{PhD} \\
\text { Monica Corazza }^{2}, \mathrm{MD}
\end{array}
$$

${ }^{1}$ Department of Medical Sciences, Section of Microbiology and Medical Genetics, University of Ferrara, Ferrara, Italy

\footnotetext{
${ }^{2}$ Department of Medical Sciences, Section of Dermatology and Infectious Diseases, University of Ferrara, Ferrara, Italy

${ }^{3}$ Pathology Division, St Anna University Hospital, Ferrara, Italy *E-mail: alessandro.borghi@unife.it
}

Conflict of interest: The authors declare that they have no conflict of interest.

doi: $10.1111 / \mathrm{ijd} .14548$ 


\section{References}

1 Nofal A, Assaf M, Ghonemy S, et al. Generalized eruptive keratoacanthoma: a diagnostic and therapeutic challenge. Int $J$ Dermatol 2015; 54: 160-167.

2 Anzalone CL, Cohen PR. Generalized eruptive keratoacanthomas of Grzybowski. Int J Dermatol 2014; 53: 131136.

3 Forslund O, DeAngelis PM, Beigi M, et al. Identification of human papillomavirus in keratoacanthomas. J Cutan Pathol 2003; 30: 423-429.

4 Stockfleth E, Meinke B, Arndt R, et al. Identification of DNA sequences of both genital and cutaneous HPV types in a small number of keratoacanthomas of nonimmunosuppressed patients. Dermatology 1999; 198: 122-125.

5 Strumì R, Roveggio C, Rotola A, et al. Keratoacanthomas: human papillomavirus and herpes simplex virus associated? $J$ Eur Acad Dermatol Venereol 1997; 8: 130-136.

6 Haas N, Schadendorf D, Henz BM, et al. Nine-year follow-up of a case of Grzybowski type multiple keratoacanthomas and failure to demonstrate human papillomavirus. Br J Dermatol 2002; 147: 793-796.

7 Cassai E, Galvan M, Trombelli L, et al. HHV6, HHV7, HHV8 in gingival biopsies from chronic adult periodontitis patients. J Clin Periodontol 2003; 30: 184-191.

8 Rotola A, Monini P, Di Luca D, et al. Presence and physical state of HPV DNA in prostate and urinary tract tissues. Int $J$ Cancer 1992; 52: 359-365.
9 Garbuglia AR. Human papillomavirus in head and neck cancer. Cancers (Basel) 2014; 6: 1705-1726.

10 lannacone MR, Gheit T, Waterboer T, et al. Case-control study of cutaneous human papillomaviruses in squamous cell carcinoma of the skin. Cancer Epidemiol Biomarkers Prev 2012; 21: 1303-1313.

11 Soler C, Chardonnet Y, Allibert P, et al. Detection of mucosal human papillomavirus types $6 / 11$ in cutaneous lesions from transplant recipients. J Invest Dermatol 1993; 101: 286-291.

12 Ferre F, Garduno F. Detection of human papillomavirus types 6/ 11,16 and 18 using the polymerase chain reaction. Cancer Cell 1989; 7: 215-218.

13 de Roda Husman AM, Walboomers JM, van den Brule AJ, et al. The use of general primers GP5 and GP6 elongated at their 3' ends with adjacent highly conserved sequences improves human papillomavirus detection by PCR. J Gen Virol 1995; 76: 1057-1062.

14 Lutzner MA, Blanchet-Bardon C, Puissant A.Oral aromatic retinoid (RO 10-9359) treatment of two patients suffering with the severe form of epidermodysplasia verruciformis. In: Orfanos $\mathrm{CE}$, Braun-Falco O, Farber EM, eds. Retinoids: Advances in Basic Research and Therapy. New York: Springer-Verlag, 1981:407-410.

15 Stellmach V, Leask A, Fuchs E. Retinoid-mediated transcriptional regulation of keratin genes in human epidermal and squamous cell carcinoma cells. Proc Natl Acad Sci USA 1991; 88: 4582-4586. 